EPJ Web of Conferences 78, 08002 (2014)

DOI: $10.1051 /$ epjconf/20147808002

(C) Owned by the authors, published by EDP Sciences, 2014

\title{
Eugene P. Wigner's Visionary Contributions to Generations-I through IV Fission Reactors
}

\author{
Frank Carré, Scientific Director, CEA - Nuclear Energy Division ${ }^{a}$ \\ Saclay Research Centre, 91191 Gif-sur-Yvette Cedex
}

\begin{abstract}
Among Europe's greatest scientists who fled to Britain and America in the 1930s, Eugene P. Wigner made instrumental advances in reactor physics, reactor design and technology, and spent nuclear fuel processing for both purposes of developing atomic weapons during world-war II and nuclear power afterwards. Wigner who had training in chemical engineering and self-education in physics first gained recognition for his remarkable articles and books on applications of Group theory to Quantum mechanics, Solid state physics and other topics that opened new branches of Physics.
\end{abstract}

\section{Manhattan Project}

After early work on neutron's energy variation in materials, Wigner really came to nuclear energy through the Manhattan Project, where he could really use his talents of theorist, experimentalist and engineer to develop the atomic weapon that was to end world-war II. Within the Metallurgical Laboratory at the University of Chicago he was tasked with theoretical and experimental research on chain reaction and with the design of nuclear reactors that would convert uranium into weapon-grade plutonium. His efforts resulted in the construction of the 100 MW B Reactor on the site of Hanford that became operational in 1944. For this reactor, Fermi wanted an air-cooled reactor, Moore and Leverett preferred using gas under pressure, while Szilard favored a liquid bismuth metal coolant similar to the system he and Einstein had patented for refrigerators. Wigner preferred a conservative design of a graphite moderated water-cooled reactor with uranium rods encased in aluminum to protect them against water corrosion. These design features were finally retained for Reactor B (Fig. 1).

Furthermore Eugene Wigner advised Glenn Seaborg and his staff of University of California chemists on solvent-extraction processes for recovering plutonium from spent nuclear fuel as they were seeking to separate traces of plutonium irradiated in cyclotrons. Although nor adopted in 1943, ion exchange and solvent-extraction processes provided foundations for postwar separation of radioisotopes and for recovering uranium and plutonium from spent nuclear fuel.

Not only Wigner's varied contributions were instrumental to the success of the Manhattan Project but they laid the foundations for key technologies, processes and reactor designs that enabled the development of Generation-I through IV fission reactors.

\footnotetext{
ae-mail: fcarre@cea.fr
} 


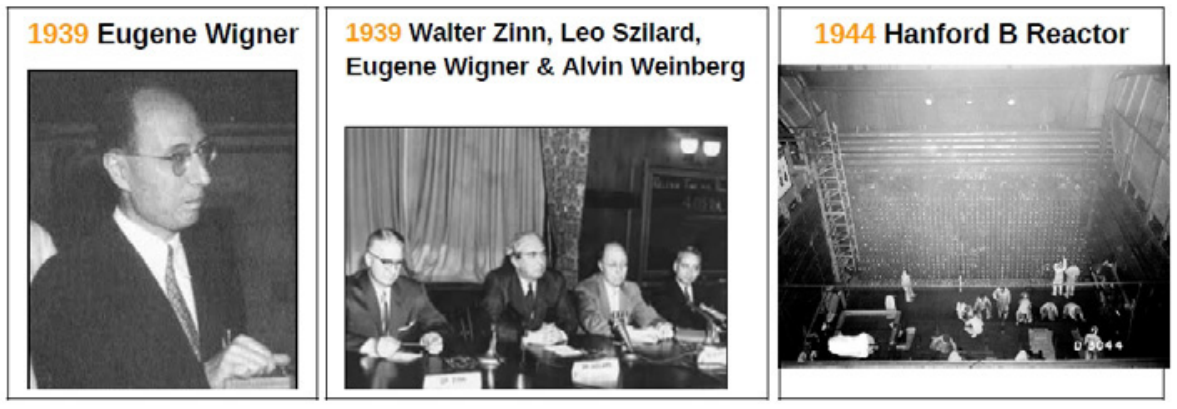

Figure 1. Eugene Wigner, Walter Zinn, Leo Szilard, Alvin Weinberg and Reactor B at Hanford.

\section{Graphite moderated reactors}

Natural uranium fuelled graphite moderated reactors (Gen-I) were directly derived from initial weapon-grade materials production reactors. This first generation of reactors benefitted from Wigner's research on nuclear physics to improve the modeling of resonances for neutron cross sections, from his understanding of irradiation damage in graphite and from his design of the B Reactor at Hanford.

The understanding of the irradiation damage in graphite led to explain the mechanism of energy storage in irradiated graphite that was then identified as "Wigner effect": atom displacements caused by neutron irradiation in graphite crystalline structure build-up energy that can be suddenly released. Annealing above $250^{\circ} \mathrm{C}$ enables atoms returning to equilibrium positions in the crystal. The Wigner effect caused fire in the Windscale nuclear plant in 1957 during an annealing operation (Fig. 2).
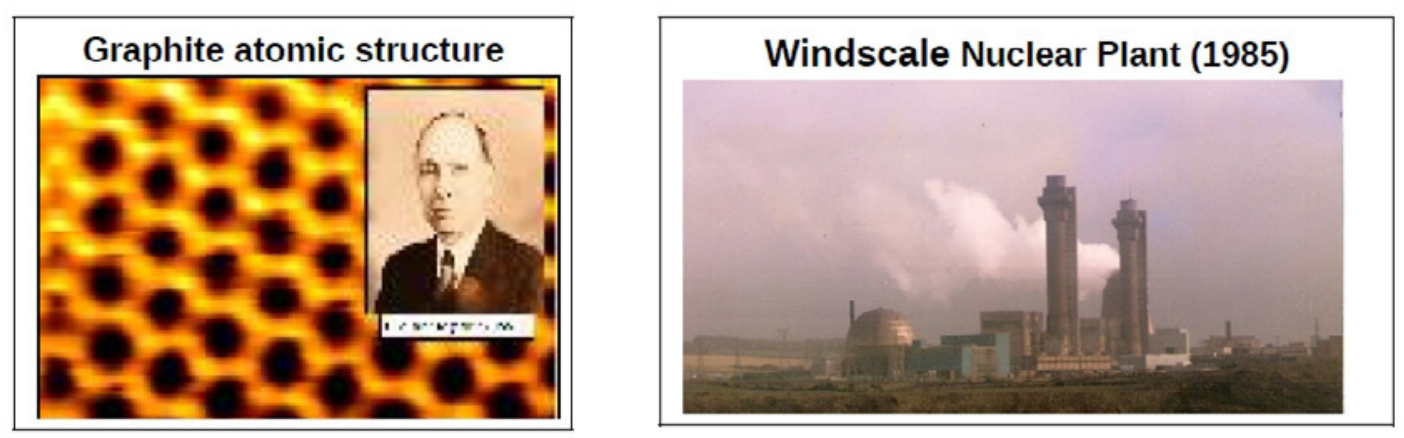

Figure 2. Graphite atomic structure subject to "Wigner effect" under irradiation and Windscale nuclear Power Plant that experienced a fire due to this effect in 1957 
Wigner 111 - Colourful \& Deep Scientific Symposium

\section{Heavy and light water reactors}

Eugene Wigner's preference for water cooling for an efficient cooling happened to lay visionary foundations to light water compact reactors that were first used to power submarines and then converted into pressurized and boiling water reactors (Gen-II PWRs \& BWRs). Indeed Eugene Wigner had considered a concept of heavy water moderated reactor (HWR) as back-up option for the B Reactor at Hanford, that happened to be precursor of a heavy water moderated / light water cooled material testing reactor in 1946 and a pool-type light water material testing reactor at Idaho National Laboratory. A pressurized version of the latter served as a basis for the core of the first nuclear submarine (Nautilus). Water moderated and cooled reactors that essentially use ${ }^{235} \mathrm{U}$ constitute $85 \%$ of the nuclear fleet in the world today and advanced versions that are currently commercialized (Gen-III) will remain the dominant type of nuclear power plant over the $21^{\text {st }}$ century (Fig. 3).

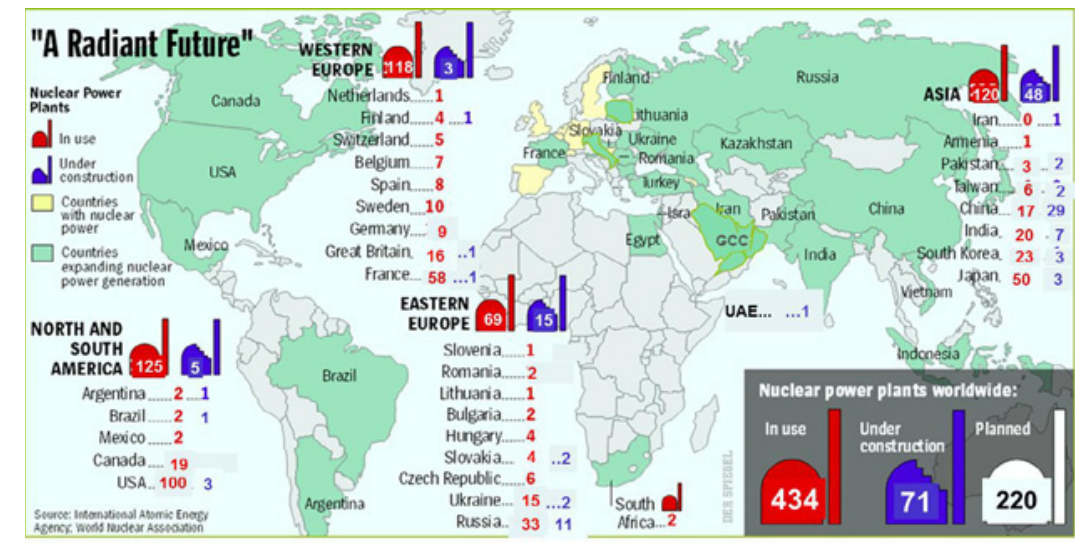

Figure 3. Operating and planned nuclear power plants in the world in 2013: 243 GWe PWRs, $\sim 83$ GWe BWRs, 21 GWe PHWRs, 11 GCRs, 11 RBMKs and 1 GWe FBRs.

Lifetime authorizations that are based on neutron damages in the steel reactor pressure vessel for this type of reactor rely on principles of irradiation science established by Wigner for his early research on graphite.

Most countries operate nuclear power plants with an open nuclear fuel cycle. In preparation for a more sustainable operation of next generation reactors, France has been reprocessing nuclear spent fuel with solvent-extraction processes since the mid-1970s with a view to recovering and recycling reusable nuclear materials (plutonium + uranium) and to partitioning ultimate radioactive waste (fission products + minor actinides) for optimum conditioning and interim storage conditions (Fig. 4).

\section{Breeder reactors and other Generation-IV reactors}

Eugene Wigner participated actively in first breeder reactor studies that originated from the belief of scarce uranium and encouraging estimated values of Fermi's neutron "Reproduction factor" $(\eta)$ for ${ }^{239} \mathrm{Pu}$ and ${ }^{233} \mathrm{U}$. He participated in early designs of breeder reactors with varied coolants $\left(\mathrm{CO}_{2}\right.$, liquid metals ...) and filed a patent $\left({ }^{27} \mathrm{P}\right)$ for sodium-cooled fast breeder reactor with metallic fuel. However, Wigner preferred $\mathrm{H}_{2} \mathrm{O}-\mathrm{D}_{2} \mathrm{O}$ moderated thermal breeders possibly homogeneous which led first in 1942 to consider a slurry of $\mathrm{UO}_{2}$ and $\mathrm{ThO}_{2}$ carried in heavy water and then in 1952 to the 


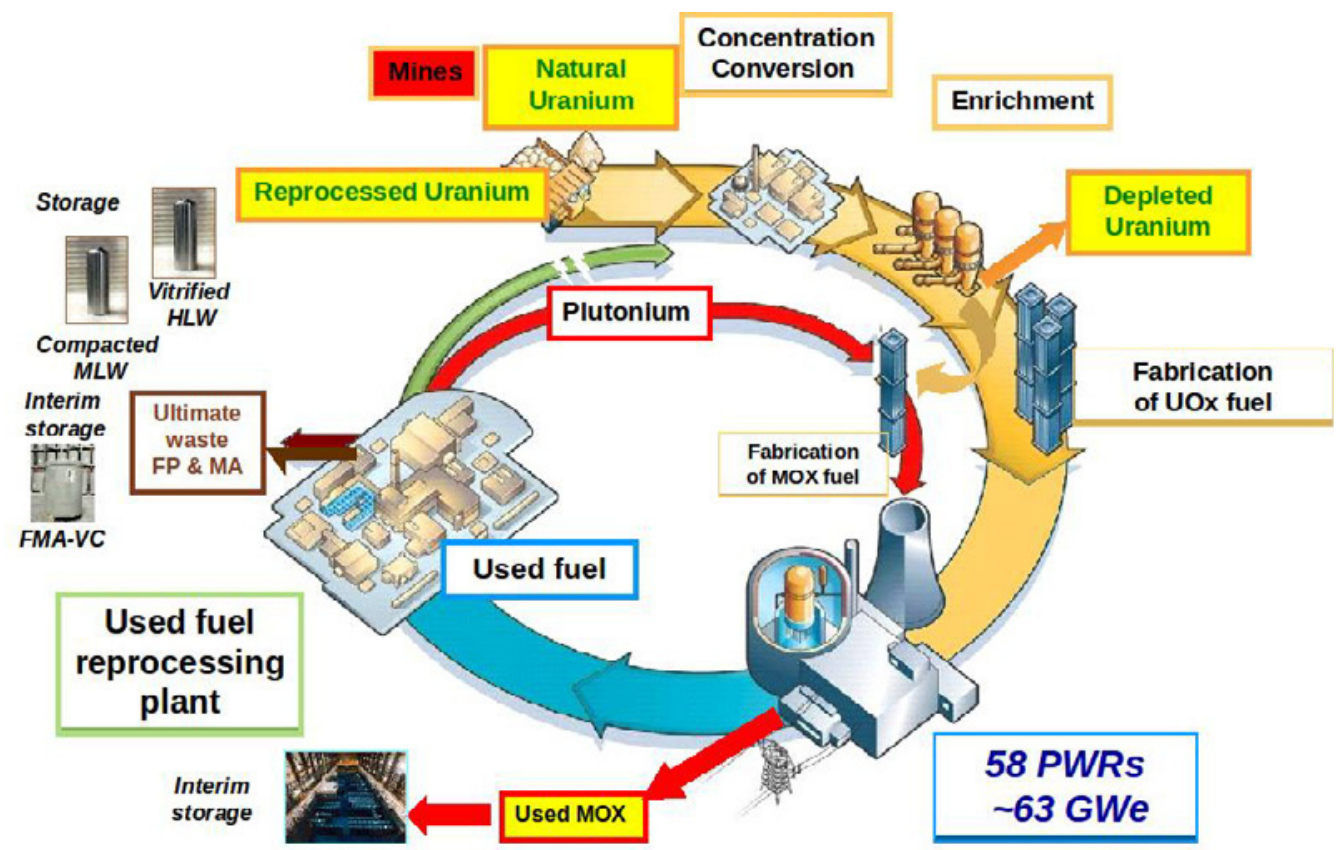

Figure 4. Nuclear fuel cycle in France based on solvent-partitioning of reusable nuclear materials (plutonium + uranium) and ultimate radioactive waste (fission products + minor actinides)

Savannah River HWR production reactor within the frame of the New Pile Committee dedicated to excess plutonium breeding reactors.

Gen-IV nuclear systems under development today encompass a wide span of reactors and fuel cycles that are anticipated to play a role over the $21^{\text {st }}$ century. Fast neutron reactors that enable using efficiently ${ }^{238} \mathrm{U}$ that represents $99.3 \%$ of uranium gave rise to demonstration sodium-cooled reactors in the United States, Europe, Russia, Japan, India and China. They are the best available technology but maybe not the ultimate vision of sustainable nuclear power. A significant effort is being made in the frame of the Generation-IV International Forum to share visions of needed improvements in safety and economics for new generations of fast neutron reactors, be they sodium-cooled, lead-cooled or gas-cooled. Wigner's contribution to fast reactors lies in precursor solvent-extraction methods for recovering plutonium from spent nuclear fuels and closing the nuclear fuel cycle.

The six baseline reactor concepts that structure cooperative research in the Generation IV International Forum are illustrated on Figure 5.

Among other Gen-IV systems, the Very/High temperature reactor that features a highly efficient energy conversion and a unique capability of supplying high temperature process heat may be viewed as today's most advanced version of early graphite moderated reactors. Here also, Wigner's pioneering work ought to be acknowledged as it contributed to consider a concept of high pressure helium-cooled highly enriched uranium / $\mathrm{BeO}$ moderated reactor that was a precursor of Dragon reactor with fuel plates, and hence a precursor of high temperature reactors before TRISO particle fuel is invented.

Molten salt reactors that where the subject of early development at Oak Ridge National Laboratory (MSRE \& MSBR) may also have initially benefitted from Wigner's advise on appropriate salt processing methods. 


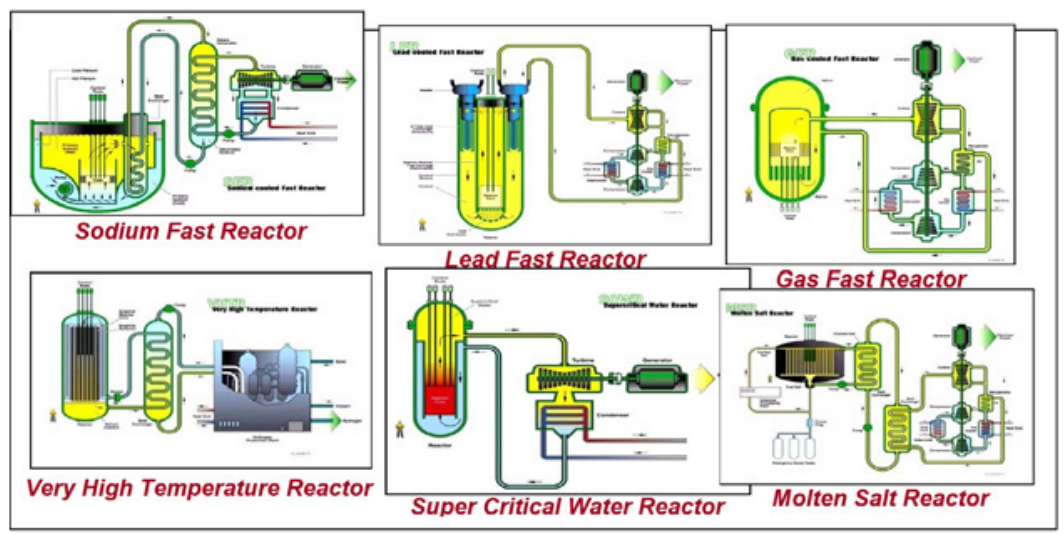

Figure 5. Basic diagram of six nuclear power systems considered for structuring cooperative research in the Generation IV International Forum.

\section{Eugene Wigner: a visionary and pathfinder for nuclear science and technology}

Among great scientists that fled Europe in the 1930s, Eugene Wigner joined cooperative international efforts to develop atomic weapons and, later, nuclear power. This significantly influenced the history of 20th century in general and the history of Oak Ridge National Laboratory in particular to the point that he was called "Patron Saint" of the Laboratory. As being outstanding in theoretical and experimental work, and being trained in both chemical engineering and physics, Wigner has been instrumental in contributing to advances in core physics, reactor design and technology, as well as spent fuel processing that supported developments of Gen-I through Gen-IV nuclear systems.

Through a few examples, this short paper evidences the wide span of theoretical and technological contributions that Wigner brought to all generation of fission reactors so far, in both fields of chemistry and physics, and how his spirit of skilled theorist and engineer will survive in nuclear systems anticipated for the $21^{\text {st }}$ century. 
